\title{
A Study to Ascertain the Practice of Hand Hygiene among MedicalStudents in Commonwealth of Dominica
}

\author{
Opeyemi Oluwabukola Afolabi ${ }^{1}$, Esther Olajumoke Adewumi ${ }^{1}$, Srinivas Medavarapu ${ }^{2 *}$, \\ Temiloluwa Oladoyin Ige ${ }^{1}$, Oluwaseyi Joy Alao ${ }^{1}$ and Olufemi Emmanuel Dada ${ }^{1}$ \\ ${ }^{1}$ Medical students, Basic Medical Sciences,All Saints University School of Medicine, Roseau, Dominica \\ ${ }^{2}$ Assistant Professor, All Saints University School of Medicine, Roseau, Dominica
}

${ }^{*}$ Corresponding author: Srinivas Medavarapu, Assistant Professor, All Saints University School of Medicine, Roseau, Dominica, Tel: 18483915130; E-mail: srinivasmedavarapu@yahoo.co.in

Received date: Sep 19, 2016; Accepted date: Sep 28, 2016; Published date: Oct 03, 2016

Copyright: (C) 2016 Afolabi OO, et al. This is an open-access article distributed under the terms of the Creative Commons Attribution License, which permits unrestricted use, distribution, and reproduction in any medium, provided the original author and source are credited.

Citation: Afolabi OO, Adewumi EO, Medavarapu S, et al. A Study to acertain the Practice of Hand Hygiene among Medical Students in Commonwealth of Dominica. Arch Med. 2016, 8:5

\section{Abstract}

Background: The practice of hand hygiene is a simple yet effective way to prevent infections. Cleaning of the hands can prevent the spread of germs, in particular those that are resistant to antibiotics and are becoming difficult, if not impossible, to treat. On the average, healthcare providers and indeed medical students clean their hands less than half of the times they should. In a day, about one in 25 hospital patients have at least one healthcareassociated infection.

Method and Findings: A cross-sectional study was carried out at All Saints University School of Medicine, Dominica. A total of 170 students from PM 1-MD5 were told to fill a questionnaire consisting of their age, gender, class, washing of hands with soap and water before eating food, washing with soap and water after urinating, washing with soap and water after defecating, washing hands after using the cadaver room, washing hands after using labs, reason for the disinfection of the body, number of illnesses in the past one year. Analysis of the result showed that medical students studied were cautious on the average towards hand hygiene and on a general note have come to embrace the importance of hand hygiene stressing on the numerous adverse effects its lack of practice have come to prove over the years.

Conclusion: A relationship between hand hygiene, illness rate, and reasons for not practicing hand hygiene is shown in the results. The current study suggests that both hand washing and the use of hand sanitizers have positive effect on the wellness of medical students. The outcomes of improved hand hygiene habits for the student result in reduced health care costs for the university since fewer students may need to utilize health center resources.

Keywords: Hand hygiene; Health care providers; Medical students; Questioner; All Saints University School of
Medicine; Health care associated infections; Hand washing; Hand sanitizers

\section{Introduction}

In 1846, a physician named Ignaz Semmelweis worked in the maternity clinic at the general hospital in vienna. Dr. Semmelweis wanted to figure out why there were so many deaths from palpebral fever in women in the hospital maternity wards commonly known as child bed fever. It was proposed that disinfection of hands could stop the transfer of disease from cadavers to pregnant women. However mortality rates of women delivered by medical students fell to the same level as those of women delivered by the midwife trainees, it was therefore necessary for all medical students to wash their hands in chlorinated lime after autopsies and before examining patients [1].

Hand hygiene involves any action of hand cleansing, rubbing your hands with an alcohol made hand rub or washing your hands with soap and water to avoid the growth of microorganisms on hands [2]. Normal hand washing with soap and water is the best component of a hand hygiene program to reduce the risk of contracting infection through contact with hands, however, there is difficulty of maintaining compliance to basic hand washing practices and this are difficulties to conquer, especially being in a school environment $[3,4]$. Practice of hand hygiene can be difficult to perform due to factors such as time constraints and the lack of wash bowl in most classroom environments. In these cases, instead of the normal hand hygiene practice of hand washing with soap and water the use of a waterless alcohol gel and hand sanitizers such as alcohol gels, offer fast, simple, and effective hand hygiene. Hammond et al. showed in a research that elementary school absenteeism due to illness was greatly reduced when the students were told to practice good hand hygiene by using an alcohol gel hand sanitizer [5]. In another study, Fendler et al. showed that alcohol gel hand sanitizers also reduced the rate at which infection transfers in an 
extended care facility where there is close proximity and direct contact between living and working in a particular place and care givers which can lead to the transfer of microbes unintentionally from one person to another [6].

There are some microorganisms not found consistently on the skin of most humans. These microorganisms are considered to be "transient flora" which is located on the superior layer of the skin and can be contracted during direct contact with clients, patients, residents, health care providers and in the environment. Transient bacteria may also be easily passed on to others or to objects in the environment and are a frequent cause of health associated infections (e.g. gramnegative bacteria, Escherichia coli). Such flora can be removed by mechanical friction of soap and water washing or eliminated by applying an antiseptic hand rub [7].

Another type of flora present is the resident flora these can be found in the deep region of the skin and are considered permanent residents of the skin. These bacteria do not generally harm and are health care associated infections that can be beneficial to the good health of the skin on most people and are not easily removed by mechanical friction. Washing of hands with water and soap removes the transient flora, but does not kill most of the resident flora on hands [7]. Hand washing has been a generally accepted practice to reduce contact transmission of microorganisms [8].

The spread of germs between humans can occur directly through hands, or indirectly through an environmental source by having contact with them (e.g. clinical equipment, opening of doors, toys etc.) [9]. It is a general fact that the hands are the major route by which spread of dangerous microorganisms can occur for example, between people, by touching pieces of equipment, etc. These can cause infections and the practice of hand hygiene is the most important factor in the prevention of infection [10]. However, research on standard hand hygiene practice among health care workers have repeatedly shown poor adherence with hand hygiene [11].

Washing of hands is of great significance means of preventing germs from spreading according to centers for disease control and prevention (CDC). CDC also recommends washing hands with soap and water for at least 15 seconds.

According to the World Health Organization, it has been estimated that washing hands with soap and water could reduce deaths caused by diarrhea by up to $50 \%$ [12]. Also, researchers in London estimated that if everyone washes their hands as a normal routine, a million deaths a year could be prevented [13]. A large percentage of outbreaks of disease caused by infected food are caused by contaminated hands. Proper hand washing practices can reduce the risk of having infected which can lead to illness and other infections [14]. Hand washing can prevent the risk of respiratory infections by $16 \%[15]$.

The centers for disease control and prevention and the association for professionals in infection control and epidemiology in the United State has clearly identified that successful hand washing practice is the most significant method of preventing the spread of diseases $[7,16]$. Teaching appropriate hand hygiene practices can promote healthy balance and have many benefits in a vast variety of places such as learning institutions, which include day cares, primary, secondary schools and universities.

Giving knowledge to people about hand washing helps them and their communities stay healthy. Hand washing education helps to:

Decrease the rate of people who get sick with diarrhea by $31 \%[17,18]$.

Decrease diarrheal illness in people with weakened immune systems by $58 \%$ [19].

Decrease respiratory infections, like common colds, in the general population by $16-21 \%[15,18]$.

\section{Method}

\section{Study area}

All Saints University School of Medicine is located in Roseau, Commonwealth of Dominica. The Island is one of the Windward Islands in the Eastern Caribbean, lying between Guadeloupe to the north and Martinique to the south. Its area is 750 square kilometers with a population density of 96 per sq. kilometer.

\section{Study population}

The estimated population of Students at All Saint University School of Medicine, Dominica is 400 .

\section{Study design}

A Cross sectional study was conducted and data was collected using a questionnaire.

\section{Sampling}

The questionnaire was distributed to a total of 170 students of All Saints University School of Medicine, Dominica.

\section{Inclusion criteria}

All Students of All Saints University School of Medicine, Dominica.

\section{Exclusion criteria}

Non Students of All Students of All Saints University School of Medicine, Dominica.

\section{Data collection}

The questionnaire distributed was self administered. The questionnaire was pretested, validated and was designed to obtain information regarding student's practice of hand hygiene, cutting across various classes, in which 5 belonged toPM1, 8 belonged to PM2, 13 belonged to PM3, 23 belonged to PM4, 51 belonged to MD1, 30 belonged to MD2, 13 belong 
to MD3, 11 belong to MD4, 16 belong to MD5. The questionnaire consisted of their ages, gender and questions involving their practice of hand hygiene.

\section{Data analysis}

The result of the questionnaire was initially compiled on excel sheet, data was imported to StatalC for analysis and was presented in the form of frequencies and percentages.

\section{Result}

\section{Profile of student interviewed}

A total of 170 subjects were examined. Volunteers consisted of 78 (45.88\%) males and 92 (54.12\%) females. The study showed that $75(44.12 \%)$, always washed their hands with soap and water before eating food, 83 (48.82\%) sometimes and $12(7.06 \%)$ never did (Table 1). Majority of those who did not wash their hands before eating gave reasons of time factor $8(66.67 \%)$ with a few of them; $3(25 \%)$ and 1 (8.33) giving reasons of not necessary and hygienic materials not available respectively (Table 2). 107 (62.94\%) and 116 (68.23\%), always washed their hands after urinating and defecating respectively with a few student lacking in these areas as shown in the data (Table 1). Those who did not wash hands after urinating, entirely gave reasons of time factor; 2 (100\%) majorly, while those who did not wash hands after defecation gave reasons of time factor; 5 (45.45\%) and feeling it was not necessary; 5
(45.45\%) as shown in Table 2. Interestingly, analysis showed that hand hygiene practice after cadaver and lab work was relatively low; only 6 (3.53\%), subjects wash their hands after using the cadaver room with $113(66.47 \%)$ of them sometimes and $51(30 \%)$ never, stating reasons of time factor; $21(41.18 \%)$, not necessary 16 (31.37\%) and hygiene material unavailable; $14(27.45 \%)$ as shown in Table 2. 94 (55.29\%), 64 (37.65\%), 5 (2.94\%) wash their hands after using the laboratory Always, Sometimes and Never respectively (Table 1). Time factor 2 (40\%), not necessary 1 (20\%) and hygienic materials unavailable 2 (40\%) were stated as reason for not washing hands after lab work (Table 2).

Table 1 Detailed distribution of answers on washing hands before and after certain activities as stated by subjects.

\begin{tabular}{|l|l|l|l|}
\hline & $\begin{array}{l}\text { Always } \\
\text { N (\%) }\end{array}$ & $\begin{array}{l}\text { Sometimes } \\
\mathbf{N}(\%)\end{array}$ & $\begin{array}{l}\text { Never N } \\
\text { (\%) }\end{array}$ \\
\hline Washing of hands before eating & $\begin{array}{l}75 \\
(44.12)\end{array}$ & $83(48.82)$ & $\begin{array}{l}12 \\
(7.06)\end{array}$ \\
\hline Washing of hands after urinating & $\begin{array}{l}107 \\
(62.94)\end{array}$ & $61(35.88)$ & $2(1.18)$ \\
\hline $\begin{array}{l}\text { Washing of hands after } \\
\text { defecation }\end{array}$ & $\begin{array}{l}116 \\
(68.24)\end{array}$ & $43(25.29)$ & $\begin{array}{l}11 \\
(6.47)\end{array}$ \\
\hline $\begin{array}{l}\text { Washing of hands after cadaver } \\
\text { work }\end{array}$ & $6(3.53)$ & $113(66.47)$ & $51(30)$ \\
\hline $\begin{array}{l}\text { Washing of hands after } \\
\text { laboratory work }\end{array}$ & $\begin{array}{l}94 \\
(55.29)\end{array}$ & $64(37.65)$ & $5(2.94)$ \\
\hline
\end{tabular}

Table 2 Comparison based on reasons for not washing hands.

\begin{tabular}{|c|c|c|c|}
\hline & Time Factor $\mathbf{N}(\%)$ & Not necessary $\mathbf{N}(\%)$ & Hygiene Materials not Available N (\%) \\
\hline Washing of hands before eating & $8(66.67)$ & $1(8.33)$ & $3(25)$ \\
\hline Washing of hands after urinating & $2(100)$ & - & - \\
\hline Washing of hands after defecation & $5(45.45)$ & $5(45.45)$ & $1(9.09)$ \\
\hline Washing of hands after using the cadaver & $21(41.18)$ & $16(3.37)$ & $14(27.45)$ \\
\hline Washing of hands after lab work & $2(40)$ & $1(20)$ & $2(40)$ \\
\hline
\end{tabular}

Table 3 Comparison between male and females that washed hands always, sometimes and never before and after activities.

\begin{tabular}{|l|l|l|l|}
\hline \multirow{2}{*}{ Gender } & $\begin{array}{l}\text { Washing } \\
\text { hands before } \\
\text { eating N (\%) }\end{array}$ & $\begin{array}{l}\text { Washing hands } \\
\text { after urinating N } \\
(\%)\end{array}$ & $\begin{array}{l}\text { Washing hands } \\
\text { after defecation N } \\
(\%)\end{array}$ \\
\hline \multirow{2}{*}{ Male } & $32(41.03)$ & $50(64.10)$ & $55(70.51)$ \\
\cline { 2 - 4 } & $41(52.56)$ & $26(33.33)$ & $17(21.79)$ \\
\cline { 2 - 4 } & $5(6.41)$ & $2(2.56)$ & $6(7.69)$ \\
\hline \multirow{2}{*}{ Female } & $43(46.74)$ & $57(61.96)$ & $61(66.30)$ \\
\cline { 2 - 4 } & $42(45.65)$ & $35(38.04)$ & $26(28.26)$ \\
\cline { 2 - 4 } & $7(7.61)$ & 0 & $5(5.43)$ \\
\hline
\end{tabular}

Based on gender there was comparison on hand washing before eating, after urinating and after defecation. Analysis for males showed that $32(41.03 \%)$ always washed their hands before eating, $41(52.56 \%)$ sometimes did and $5(6.41 \%)$ never did, while for females 43 (46.74\%) always, 42 (45.65\%) sometimes and 7 (7.61\%) never washed their hands before eating food. Again for males, 50 (64.10\%) always, 26 (33.33\%) sometimes and $2(2.56 \%)$ never washed their hand after urinating, while $57(61.96 \%)$ and 35 (38.04\%) of females always and sometimes did respectively. The number of males that washed their hands after defecation were; 55 (70.51\%) always, $17(21.79 \%)$ sometimes and 6 (7.69\%) never while females 61 $(66.30 \%)$ always, $26(28.26 \%)$ sometimes and $5(5.43 \%)$ never (Table 3).

The reasons provided in the questionnaire for not washing hands were time factor, feeling it was not necessary and hygiene materials unavailable. 12 (7.06\%) students did not wash hand before eating, $2(1.18 \%)$ did not wash hands after urinating, 11 (6.47\%) did not wash hands after defecation, 51 
(30\%) did not wash hands after cadaver work and 5 (2.94\%) did not wash hands after laboratory work.

When subjects were asked if they had illnesses in the past one year 121 (71.18\%) answered yes, 48 (28.24\%) no and 1 (0.59\%) maybe. A number of them 83 (48.82), 87 (51.18\%), thought this illnesses could have been prevented by practicing proper hand hygiene; yes and no respectively. 61 (50.41\%), 22
(45.83\%) who thought diseases were preventable by hand hygiene fell ill 0-2 and 3-5 times respectively, while those who thought diseases were not preventable by hand hygiene 60 (49.59\%), 26 (54.17\%) and 1 (100\%) were ill 0-2, 3-5 and more than 5 times respectively (Table 4). 100 (58.82\%), 60 (35.29\%), $10(5.88 \%)$ think good hygiene will affect their future careers as medical doctors yes, no and maybe respectively.

Table 4 Comparison on the number of diseases in the last one (1) year based on the perception of subjects as being preventable by hand hygiene or not preventable by hand hygiene.

\begin{tabular}{|l|l|l|l|}
\hline & $\mathbf{0 - 2}$ times N (\%) & $\mathbf{3 - 5}$ times N (\%) & More than 5 times N (\%) \\
\hline Preventable by Hand Hygiene & $61(50.41)$ & $22(45.83)$ & 0 \\
\hline Not Preventable by Hand hygiene & $60(49.59)$ & $26(54.17)$ & $1(100)$ \\
\hline
\end{tabular}

\section{Discussion}

The results obtained from this study show a statistically significant increase in the practice of hand washing and hand sanitizer use among students.

Interestingly, there were number of students that did not practice good hand hygiene especially after cadaver and laboratory work. Some students had their own personal bottles either in their room or in their purses or pockets. It should be mentioned that illness were based on self-reporting by students and that no clinical confirmation of these illnesses were obtained from the students.

This study however showed that medical students who were not conscious of their hand hygiene were prone to infections which in turn can be responsible for the spread of infections amongst colleagues and their patients leading to hospital acquired infections (HAI) [20-22]. amongst several factors, poor hand hygiene is responsible for a number of infections including those from; Staphylococcus aureus, MRSA, Klebsiella, Bacillus anthracis, Escherichia coli, Pseudomonas, Clostridium difficle, Candida spp, Enterococcus and enveloped viruses [23]. Studies have proposed that diseases reduce by washing of hands with soap and water in the presence of visible dirt or contamination (with proteinous material, blood, body fluids), after using the restroom, and before and after having food. The washing of hands with soap and water after; urination, defecation, laboratory work, using the cadaver room is important for medical students because it is the simplest and least expensive means of reducing the prevalence of diseases among medical students and the spread of hospital acquired infection in particular the organisms that are antimicrobial resistant [20-22,24-27].

Recent research has proposed that the adherence of health care workers to the recommended hand washing practices remains unacceptably, low, rarely exceeding $40 \%$ in which hand hygiene is indicated $[28,29]$ which is in correlation with this study. A number of authors have linked good hand hygiene practice to display of signs and indication for awareness purpose. In a research by de Mortel [30] it was observed that $63 \%$ of medical students were aware of the correct indications for hand hygiene while Mann and Wood [31] reported awareness in only $56 \%$ of students.

In a study carried out by Azzam and Sajad [32], only $29 \%$ of medical students were able to identify all indications of hand hygiene, [32] while in another carried out by Graf et al. 33\% could identify indications of hand hygiene [33]. Feather et al. carried out a study on 187 it was discovered that only $8.5 \%$ washed their hands after contact with patient, however, it increased to $18.3 \%$ when hand hygiene signs were displayed [34].

A relationship between hand hygiene, illness rate, and reasons for not practicing hand hygiene is shown in the results. The current study suggests that both hand washing and the use of hand sanitizers have a positive effect on the wellness of University students. The outcomes of improved hand hygiene habits for the student result in reduced health care costs for the university since fewer students may need to utilize health center resources. Thus, the impact of improved hand hygiene should be considered within the context of general health behaviors.

A limitation for this study as described by de Mortel [30] amongst other authors is the distortion of results due to the false answers provided by subjects probably because of social approval.

\section{Conclusion and Recommendation}

Through hand hygiene education and provision of an alcohol gel hand sanitizer product, promotes general wellness of an individual reducing the spread of infections in the health care system and beyond laying emphasis on the fact that a number of infections owe their route of transmission to poor hand hygiene and infact are implicated in life threatening infections.

This research recommends that for successful interventions to be promoted there should be more research into the factor determining the behaviors of medical student and practitioners in order to improve hand hygiene. The importance of hand hygiene should also be included in undergraduate syllabus so that medical students know its importance. Large scale systematic studies should be carried 
out to identify the reasons thereof and plan remedial strategies. There is also need for mentoring of medical students by their seniors to enable them know the importance of the scope and influence the positive behavior in medical students.

\section{Acknowledgment}

Corresponding authors would like to thank David Otohinoyi (clinical student) for his contribution in the analysis of the results.

\section{References}

1. WHO (2000) Hospital epidemiology service.

2. Pittet D, Allegranzi B, Boyce J (2009) The WHO guidelines on hand hygiene in health care and their consensus recommendations. Infect Control Hosp Epidemiol 30: 611-622.

3. Day RA, St Arnaud S, Monsma M (1993) Effectiveness of a handwashing program. Clin Nurs Res 2: 24-40.

4. Monsma M, Day R, St Arnaud S (1992) Handwashing makes a difference. J Sch Health 62: 109-111.

5. Hammond B, Ali Y, Fendler E, Dolan M, Donovan S (2000) Effect of hand sanitizer use on elementary school absenteeism. Am J Infect Control 28: 340-346.

6. Fendler EJ, Ali Y, Hammond BS, Lyons MK, Kelley MB, et al. (2002) The impact of alcohol hand sanitizer use on infection rates in an extended care facility. Am J Infect Control 30 : 226-233.

7. Larson EL (1995) APIC guideline for handwashing and hand antisepsis in health care settings. Am J Infect Control 23: 251-269.

8. Larson E (1988) A causal link between hand washing and risk of infection. Examine the evidence. Infection Control, Hospital Epidemiology 9: 28-36

9. Loveday HP, Wilson JA, Pratt RJ, Golsorkhi M, Tingle A, et al. (2014) epic3: National evidence-based guidelines for preventing healthcare-associated infections in NHS hospitals in england. J Hosp Infect 86: S1-S70.

10. Weston D (2013) Fundamentals of Infection Prevention and Control (2nd Edtn), Oxford Wiley Blackwell, USA.

11. Damani N (2012) Manual of Infection Prevention and Control (3rd Edition) Oxford University Press, USA.

12. WHO (2001) Water for health: taking charge.

13. Curtis V, Cairncross S (2003) Effect of washing hands with soap on diarrhoea risk in the community: a systematic review. Lancet Infect Dis 3: 275-281.

14. WHO (2000) Foodborne disease: a focus for health education.

15. Rabie T, Curtis V (2006) Handwashing and risk of respiratory infections: a quantitative systematic review. Trop Med Int Health 11: 258-267.

16. Garner JS, Favero MS (1986) CDC Guideline for handwashing and hospital environmental control, 1985. Infect Control 7: 231-243.
17. Ejemot RI, Ehiri JE, Meremikwu MM, Critchley JA (2008) Hand washing for preventing diarrhea. Cochrane Database Syst Rev 1: CD004265.

18. Aiello AE, Coulborn RM, Perez V, Larson EL (2008) Effect of hand hygiene on infectious disease risk in the community setting: a meta-analysis. Am J Public Health 98: 1372-1381.

19. Huang DB, Zhou J (2007) Effect of intensive handwashing in the prevention of diarrhoeal illness among patients with AIDS: a randomized controlled study. J Med Microbiol 56: 659-663.

20. Guide to implementation of the WHO multimodal hand hygiene improvement strategy.

21. WHO Guidelines on Hand Hygiene in Health Care. First Global Patient Safety Challenge. Clean Care is Safer Care.

22. Boyce JM, Pittet D (2002) Guideline for hand hygiene in healthcare settings. Recommendations of the healthcare infection control practices advisory committee and the HICPAC/SHEA/ APIC/IDSA hand hygiene task force. Morb Mortal Wkly Rep 51:1-44.

23. Mathur P (2011) Hand hygiene: back to the basics of infection control. Indian J Med Res 134: 611-620.

24. Smith SM (2009) A review of hand-washing techniques in primary care and community settings. J Clin Nurs 18: 786-790.

25. Canada: Laboratory Centre for Disease Control, Bureau of Infectious Diseases; 1998. Infection control guidelines. Communicable disease report.

26. Larson E (1999) Skin hygiene and infection prevention: more of the same or different approaches? Clin Infect Dis 29: 1287-1294.

27. Larson E (1988) A causal link between handwashing and risk of infection. Examination of the evidence? Infect Control HospEpidemiol 9: 28-36.

28. Trampuz A, Widmer AF (2004) Hand hygiene: a frequently missed lifesaving opportunity during patient care. Mayo Clin Proc 79: 109-116.

29. Pittet D, Mourouga P, Perneger TV (1999) Compliance with handwashing in a teaching hospital. Infection control program. Ann Intern Med 130: 126-130.

30. van de Morte IT (2009) Development of a questionnaire to assess health care students hand hygiene knowledge, beliefs and practices. Aust J Adv Nurs 26: 9-16.

31. Mann CM, Wood A (2006) How much do medical students know about infection control? Journal of Hospital Infection 64: 366-370.

32. Al-kadi A, Salati SA (2012) Hand hygiene practice among medical students. Interdisciplinary perspective in infectious disease.

33. Graf K, Chaberny IF, Vonberg RP (2011) Beliefs about hand hygiene: a survey in medical students in their first clinical year. Am J Infect Control 39: 885-888.

34. Feather A, Stone SP, Wessier A, Boursicot KA, Pratt C (2000) Now please wash your hands': the hand washing behaviour of final MBBS candidates. J Hosp Infect 45: 62-64. 